\title{
JEJAK DIASPORA DAN NARASI KEHIDUPAN PICTURE BRIDES DALAM NOVEL THE BUDDHA IN THE ATTIC KARYA JULIE OTSUKA
}

\author{
Sindhy Sintya Mianani \\ Magister Kajian Sastra dan Budaya Universitas Airlangga \\ sindhysintya@gmail.com
}

\begin{abstract}
Abstrak
Amerika Serikat yang dikenal sebagai negeri para imigran telah menarik jutaan imigran yang bermimpi untuk memiliki masa depan cerah ke pesisir negaranya. Sebagai negeri para imigran, pengalaman diaspora para imigran di Amerika sejatinya merupakan topik yang telah banyak dieksplorasi dalam dunia kesusastraan. Akan tetapi, sedikit sekali yang berbicara mengenai diaspora warga Jepang di Amerika. Sebagai sebuah awalan, studi ini menguraikan pengalaman diaspora para perempuan Jepang yang mengadu nasib di daratan Amerika sebagai picture brides dalam novel The Buddha in the Attic karya Julie Otsuka. Tidak hanya berbicara mengenai kehidupan picture brides di Amerika, The Buddha in the Attic juga menceritakan pengalaman imigran Jepang pada masa Perang Dunia II yang berujung pada kamp-kamp konsentrasi. Untuk menguraikan permasalahan tersebut, studi ini menerapkan teori Historical Poetics yang diprakarsai oleh Alan Swingewood untuk memperoleh hasil analisis yang rigid. Dikemas dengan subjek orang pertama jamak (first person plural), Julie Otsuka menciptakan sebuah narasi tentang kehidupan para picture brides dan imigran Jepang secara kolektif. Tindakan yang dilakukan sang penulis ini, disinyalir sebagai bentuk post-memory-nya sebagai generasi ketiga imigran Jepang (sansei) di Amerika.
\end{abstract}

Kata kunci: diaspora, narasi, historical poetics, picture brides, post-memory

\begin{abstract}
United States of America which is acknowledged as the land of immigrants has lured millions of those who seek for a bright future to its coast. As the land of immigrants, diaporic phenomenon in America has been explored extensively in literary world. However, a very few number has yet to conduct a study on Japanese diasporic phenomenon in America. To begin with, this study attempts to describe the diaporic phenomenon of Japanese women who came to America as picture brides in Julie Otsuka's The Buddha in the Attic. Not only narrating the the story of picture brides in America, The Buddha in the Attic also tells the story of Japanese migrants who ended up in concentracion camps during the Word War II period. To solve the problem aforementioned, this study applies Alan Swingewood's Historical Poetics to get adequate results. As the novel is written in Girst person plural prounoun, Julie Otsuka is said to create narratives on Japanese picture brides and Japanese migrants collectively. What the author does is assumed as the post-memory of being the third generation of Japanese migrants (sansei) in America.
\end{abstract}

Keywords: diaspora, narratives, historical poetics, picture brides, post-memory 
Poetika: Jurnal Ilmu Sastra

Vol. VII No. 2, Desember 2019
DOI 10.22146/poetika.49352

ISSN 2338-5383 (print); 2503-4642 (online)

\section{Pendahuluan}

Amerika selama ini dikenal sebagai benua bagi para imigran yang datang dengan tujuan untuk memperoleh kehidupan yang lebih baik. Bagi para imigran, Amerika merupakan daratan baru yang menawarkan kesempatan untuk menggapai impian dan harapan mereka yang tertunda di tanah asal mereka. Berbekal impian dan harapan, mereka berbondong-bondong datang ke The New World yang terkenal dengan gaung kesuksesan yang ditawarkan oleh American Dream (Cullen, 2003).

Pengalaman diaspora di Amerika Serikat sendiri merupakan fenomena yang telah banyak dieksplorasi maupun dikaji oleh para peneliti. Tidak sedikit pengalaman diaspora yang dialami oleh para imigran Amerika ini juga didokumentasikan oleh para pengarang maupun sejarawan, seperti Alice Walker, V. S. Naipaul, Victoria Chang, maupun Cyntia Kadohata. Tak jarang, pengalaman pribadi mereka disisipkan ke dalam karya-karya mereka, entah itu berupa kesulitan-kesulitan hidup maupun mozaik impian-impian sebagai imigran di Amerika Serikat. Sebabnya, para penulis merupakan bagian dari suatu masyarakat itu sendiri (a salient being).

Amerika Serikat merupakan daya tarik tersendiri bagi para imigran yang datang untuk mengadu nasib. Adalah American Dream yang menjadi pesona Amerika dengan jargon yang menarik jutaan imigran ke daratan Amerika Serikat, "that all men are created equal that they are endowed by their Creator with certain unalienable rights, that among these are life, liberty and the pursuit of happi- ness" (Jefferson, 1776: 1). Ditambah lagi, Amerika Serikat juga dikenal dengan nama The New World (Cullen, 2003). Dimotivasi oleh keinginan paling dasar, yaitu impian untuk memperoleh kehidupan yang lebih baik, menjadi daya tarik utama bagi para imigran yang datang berbodong-bondong menuju A.S (Clark, 2003: 3).

Fenomena migrasi di Amerika Serikat telah diawali oleh ketiga belas koloni dari Inggris pada abad ke-16. Ratu Elizabeth mengutus pasukan ekspedisi untuk membentuk koloni di Amerika bagian utara. Dalam masa settlement di daratan Amerika, ketiga belas koloni tersebut mengalami kesulitan dalam proses membangun dan mengelola tanah sehingga mereka mendatangkan orang-orang Afrika untuk mengatasi kesulitan tersebut. Dari praktik slavery inilah, secara tidak langsung terjadi proses migrasi warga Afrika ke Amerika.

Selain migrasi dari Inggris dan Afrika, terdapat pula fenomena migrasi warga Asia. Fenomena diaspora warga Asia di Amerika dimulai pada tahun 1850 yang diawali dengan ditemukannya catatan sejarah mengenai migrasi warga negara China kemudian disusul oleh migrasi warga Jepang pada tahun 1885 yang disertai juga dengan migrasi warga Korea dan India. Hingga yang terakhir disusul oleh migrasi warga Filipina pada tahun 1924. Mayoritas alasan perpindahan tersebut adalah pekerjaan. Amerika yang sedang berupaya untuk membangun negaranya membutuhkan banyak pekerja serabutan. Kesempatan inilah yang mendorong sebagian besar warga Asia mengadu nasib di daratan Amerika (Okihiro, 2001: 5).

Selain faktor pekerjaan, salah satu penyebab fenomena migrasi warga Asia ke Amerika ialah 
picture marriage pada era Perang Dunia II. Picture marriage merupakan salah satu faktor penyebab terjadinya fenomena migrasi pada saat Perang Dunia II, khususnya bagi para perempuan yang berasal dari Asia Timur, seperti negara China, Korea, dan juga Jepang. Picture marriage dapat dikatakan sebagai sebuah evolusi praktik perjodohan atau arranged marriage bagi negara-negara ini semenjak ditemukannya kamera (Fagler, 2018: 11). Praktik perjodohan picture marriage ini selalu melibatkan seorang perempuan yang disebut dengan picture bride atau dikenal juga dengan mail-order bride.

Dengan adanya fenomena diaspora imigran Jepang dan juga Japanese picture brides ke Amerika, dalam ranah sastra dan budaya terdapat pula novel berjudul Picture Bride karya Yoshiko Uchida dan sebuah film berjudul Picture Bride karya Kayo Hatta yang juga bercerita tentang kehidupan para picture brides di Amerika. Menurut Kiyoto Sato (2015), kedua karya yang terkenal ini merupakan sebuah novel dan film bertema sejarah yang mengandung narasi mengenai kehidupan picture brides sebagai imigran Jepang di Amerika. Baik novel maupun film yang berjudul Picture Bride ini merepresentasikan fenomena picture brides Jepang sebagai sosok yang mengalami penindasan rasial. Hal ini tentu saja meleburkan fakta sejarah dan fiksi karena tidak sepenuhnya merepresentasikan picture brides sebagai sosok penting dalam sejarah komunitas imigran Jepang di Amerika mengingat bahwa pengarang pasti memodifikasi fakta sejarah sebagai hasil dari post-memori yang mereka dapatkan sebagai entitas kolektif.

Selain leburnya fakta sejarah dan fiksi dalam novel-novel yang menceritakan kehidupan picture brides, sebuah kajian etnografi mengenai sejarah lisan picture brides yang ditulis oleh Ikumi T. Yanagisawa (2010) berusaha meminimalisasi permasalahan ini dengan mengumpulkan data-data sejarah yang berasal dari para picture brides Jepang yang masih hidup dan tinggal di Amerika. Selain Yanagisawa, Jemma Fagler (2018) juga melakukan hal yang serupa, tetapi Fagler lebih menekankan diskusinya pada faktor-faktor eksternal seperti kebijakankebijakan pemerintah Amerika yang mengatur para imigran Jepang generasi pertama.

Terkait dengan kajian-kajian tersebut, fenomena diaspora imigran Jepang generasi pertama (Issei), termasuk picture brides, dan juga regulasi yang mengatur mereka selama tinggal di Amerika ini dimanifestasikan oleh seorang pengarang Amerika keturunan Jepang, Julie Otsuka dalam novelnya yang berjudul The Buddha in the Attic. The Buddha in the Attic menceritakan pengalaman perempuan-perempuan Jepang yang menjajal peruntungan dengan hidup sebagai picture brides di Amerika. Dengan bermodalkan foto-foto "riil" dari calon suami mereka, mereka menempatkan harapan untuk memperoleh kehidupan yang lebih baik di Amerika.

Julie Otsuka memang bukanlah generasi yang mengalami pahitnya pengalaman para imigran Jepang generasi pertama dan kedua di Amerika. Akan tetapi, sebagai salah satu anggota dari imigran Jepang generasi ketiga, ia merasa memiliki hak otoritatif untuk berbicara mengenai hal ini. Berangkat dari memori para 
imigran Jepang generasi pertama, termasuk di dalamnya para picture brides, dan kedua, Julie Otsuka sebagai generasi ketiga menggunakan post-memory-nya untuk memberitahu dunia tentang sejarah kelam ini.

Mengutip pernyataan Hirsch, pengalaman traumatis dan hubungan darah memiliki pengaruh dalam pembentukan post-memory seseorang. Karena bersifat familial, pewarisan ingatan didasarkan pada hubungan darah antargenerasi. Selain pewarisan yang bersifat familial, pewarisan yang bersifat afiliatif juga turut mengambil peran dalam terciptanya post-memory seseorang. Pewarisan yang bersifat afiliatif didapatkan dari pihak otoritatif lain yang "berhak" memberi versi sejarah yang benar, seperti negara atau instansi khusus lainnya. Akan tetapi, perlu diketahui pula bahwa terdapat mediasi yang dilakukan oleh generasi post-memory untuk merekonstruksi masa lalu yang traumatis. Dalam mediasi inilah terjadi penambahan, kritik, atau klarifikasi yang dilakukan sehingga usaha post-generasi untuk memperbaiki masa lalu tersebut bisa terpenuhi (Hirsch, 2012: 85).

Melihat pernyataan tersebut, dapat dikatakan bahwa Julie Otsuka berusaha membangun sebuah narasi sebagai postgenerasi dari sejarah kelam migrasi warga Jepang di Amerika, terutama melalui pengalaman diaspora picture brides. Sebagai tambahan, pengalaman diaspora para picture brides ini dikemas dengan menggunakan subjek kolektif "we" oleh Julie Otsuka. Merupakan hal yang menarik ketika mayoritas penceritaan pada novel menggunakan sudut pandang orang pertama $(I)$, kedua (you), maupun orang ketiga serba tahu (omnipresent), The Buddha in the Attic memiliki bentuk narasi yang berbeda dengan novel kebanyakan. Penggunaan subjek kolektif ini merujuk kepada representasi kelompok, yaitu para Japanase picture brides dan kemudian bergeser untuk merepresetasikan para imigran Jepang di Amerika secara kolektif.

Berdasarkan paparan tersebut, dapat dilihat bahwa dalam The Buddha in the Attic terdapat dua buah topik prominen yang dieksplorasi oleh Julie Otsuka, yaitu fenomena diaspora para picture brides di Amerika dan juga penggunaan orang pertama jamak, "we", dalam narasinya. Kedua hal tersebut memiliki keterkaitan dengan bagaimana The Buddha in the Attic menjadi sebuah karya sastra yang tidak hanya dibentuk oleh sejarah, tetapi juga memengaruhi sejarah itu sendiri. Dengan narasi yang menjabarkan kesulitan yang dialami para picture brides dan juga imigran Jepang di Amerika, jelas nampak bahwa terdapat sebuah upaya untuk membuat narasi mengenai kehidupan para imigran Jepang (Nikkei-jin) di Amerika Serikat.

\section{Kerangka Pemikiran Teoretis}

Untuk menjawab permasalahan seperti yang telah dipaparkan pada bagian sebelumnya, studi ini juga menerapkan pendekatan sosiologi sastra yang diajukan oleh Alan Swingewood. Alan Swingewood dalam Sociological Poetics and Aesthetics Theory (1987) membagi diskusinya menjadi beberapa pokok bahasan, salah satunya mengenai sejarah dan teks sastra dalam sub-bab yang berjudul "Historical Poetics". Karena studi ini berkaitan 
dengan sejarah imigrasi warga Jepang ke Amerika Serikat, pemilihan teori ini dianggap paling sesuai untuk menjawab pertanyaanpertanyaan yang telah diajukan pada bagian sebelumnya.

Menurut Alan Swingewood, keterkaitan antara sejarah dan karya sastra merupakan sebuah hubungan timbal balik layaknya konsep Mikhail Bakhtin akan dialogisme. Swingewood berpendapat bahwa novel atau teks sastra secara aktif berkontribusi kepada pembentukan bahasa di masyarakat-yang sudah pasti mengandung tujuan atau ideologi tertentu-karena adanya kerjasama antara budaya dan politik. Selain faktor tersebut, adanya keterbukaan dan struktur sosial yang dinamis dalam suatu masyarakat turut mempengaruhi peranan aktif novel terhadap masyarakat. Maka dari itu, menurut Swingewood, Historical Poetics adalah

... a method combining both genetic and structuralist analysis, objective and empirical, generating hypotheses which can be tested without recourse to the intuition of the educated critic. It suggests a model of socio-cultural specificity incorporating the institutions, and the practices, of the extraliterary systems, the traditions of a culture (with their modes of reproduction and transmission) and the major and minor literary and artistic genres. The model is not an ideal type, an abstraction of the most significant features of socio-cultural configuration, but one which is structured around the notion of historical specificity (Swingewood, 1987: 102).

Lebih lanjut, Swingewood juga berpendapat bahwa pengaplikasian metode yang dikenalkan oleh Lucien Goldmann menjadi relevan dalam studi yang menggunakan metode Historical Poetics. Metode Goldmann, yang diadaptasi oleh Historical Poetics, mencoba menjawab keterkaitan antara teks sas- tra dan sejarah dengan berpindah dari sebuah model ke kenyataan sejarah dan menjelaskan material yang lebih beragam secara empiris. Dengan demikian, karya seni dan teks sastra dianalisis dalam konteks sejarah dan hubungan sinkroniknya dengan model. Hal ini bukanlah untuk membangun pandangan positivistik maupun pendekatan empiris kepada pembangunan metode dan model. Pasalnya, tugas dari Historical Poetics bukanlah mengenai seberapa banyak pengetahuan eksternal karya sastra maupun karya seni, atau secara sederhana pengetahuan tentang karya sastra. Tugas dari Historical Poetics adalah menggambarkan dan memahami asal-usul sturuktur, dan pentingnya budaya tentang masa lalu yang memengaruhi masa kini (living present).

Swingewood pun menambahkan bahwa masing-masing genre novel sebenarnya memiliki fungsi "to mediate historical continuity, human consciousness and tradition" (1987: 106). Artinya, masing-masing genre mengandung elemen-elemen archaic yang diabadikan dan diperbarui melalui kontak dengan realitas sejarah dan budaya melalui penciptaan karyakarya baru milik tradisi.

Melalui tradisi, penulis secara aktif mengubah dan memodifikasi masa lalu dengan karyakarya baru dan inovatif. Mereka secara aktif mengubah persepsi masa lalu dan membentuk apa yang oleh Eliot disebut sebagai "ideal order" atau tatanan ideal. Dengan kata lain, tradisi menjembatani biografi pengarang, situasi kelas, konteks sejarah, dan penciptaan sastra yang menempatkan penulis sebagai pencipta yang merespons budaya hidup melalui "knowledge alive with understanding" (1962: 
42). Pada akhirnya, tradisi "is not simply there but is made and remade in a process of constant structuration through collective human activity" (Swingewood, 1987: 112).

Dengan adanya keterkaitan antara tradisi dan kecenderungannya untuk diproduksi ulang melalui sebuah teks sastra, ia pun secara tidak langsung berkaitan dengan konsep hegemoni. Sebagai proses yang dijalani, hegemoni juga akan selalu memiliki hubungan konkret dengan formasi kelas social dan sejarah karena ia merupakan proses yang melibatkan subjek yang aktif dalam wacana praktis sehari-hari. Seperti yang dikemukakan oleh Williams bahwa hegemoni berhubungan dengan "specific distributions of power and influence" (1977: 108), hegemoni pada akhirnya, seperti halnya tradisi, menjaga kesinambungan budaya dan sejarah.

Apa yang dipaparkan oleh Swingewood mengenai genre, tradisi, budaya, dan hegemoni ini kemudian mengarah kepada unsur prominen pencipta karya sastra, yaitu pengarang (author). Pegarang, menurut Swingewood, merupakan subjek kolektif yang dalam hubungan dialogisnya berinteraksi dengan masyarakat; dan sebaliknya. Dengan demikian, pengarang sebagai bagian dari masyarakat (kolektif) dipengaruhi dan memengaruhi satu sama lain melalui interaksinya dengan budaya, tradisi, dan komunitasnya. Semua unsur ini saling bekerja sama secara timbal balik untuk membentuk sebuah karya sastra. Dengan demikian, salah satu permasalahan mendasar dari Historical Poetics adalah "historisitas" karya sastra beserta makna yang dimilikinya pada ma- sa lalu dan masa kini.

Dengan adanya "historisitas" karya sastra beserta makna yang dimilikinya pada masa lalu dan masa kini, terdapat pula kemungkinan bahwa penulis sebagai pencipta karya sastra berusaha untuk memperbaiki masa lalu. Dalam hal ini, seorang pengarang mendapat transmisi untuk menciptakan karyanya menjadi signifikan. Hirsch menawarkan jawaban atas pertanyaan itu di mana post-generasi membawa misi untuk memperbaiki masa lalu. Artinya, seorang pengarang, sebagai bagian dari masyarakat, seolah punya hak otoritatif untuk berbicara mengenai peristiwa-peristiwa sejarah yang terjadi di sekitarnya.

Berdasarkan pendapat Hirsch (2012: 8586), transmisi pengalaman yang traumatis dapat memengaruhi proses pencipaan karya estetik sebagai perwujudan identifikasi. Setelah mendapatkan transmisi, post-generasi akan melakukan rekonstruksi. Dalam melakukan rekonstruksi, memori yang sudah ditransmisikan kepada generasi yang tidak mengalami pengalaman tersebut, termediasi dengan ingatan mereka sendiri. Dalam proses mediasi inilah terjadi penambahan, kritik, atau klarifikasi yang dilakukan. Di dalam post-memori, identifikasi yang dilakukan post-generasi merupakan identifikasi yang menarik Diri (Self) keluar dari diri dan berempati kepada masa lalu (Other), bukan sebaliknya. Untuk itu, ketika pengarang menciptakan karya yang berdasar dari post-memori yang ia terima, akan selalu ada usaha untuk merekonstruksi masa lalu.

\section{Metode}

Berdasarkan uraian-uraian yang telah 
dikemukakan sebelumnya, metode yang digunakan dalam studi ini adalah metode thick description yang dikenalkan oleh Clifford Geertz (1998: 1253-1278). Metode thick description digunakan untuk menguak apa saja ide-ide kebudayaan di balik fenomena budaya. Metode thick description digunakan sebagai bentuk kompensasi dari metode pembacaan dekat (close reading) yang dikembangkan oleh New Criticism. Thick description menghubungkan kode-kode kebudayaan (cultural codes) dalam teks yang dianalisis dengan cara merekonstruksi beragam praktik sosio-kultural yang tersirat dalam teks (Budianta, 2006: 10-11).

Analisis data juga diperkuat dengan metode hermeneutika yang dikembangkan oleh Paul Ricoeur. Konsep Ricoeur tentang hermeneutika menyebutkan bahwa tujuan utama dari interpretasi adalah untuk memahami sifat dari sebuah wacana, aspekaspek yang terkait dengan teks, proses pemahaman tekstual, dan kondisi subjektif dalam memahami sebuah teks. Dengan memberi perhatian lebih kepada hal-hal tersebut, sebuah interpretasi barulah dapat dikatakan memiliki hasil yang rigid (Klemm, 1983: 74108).

Pemilihan metode dalam studi ini didasarkan pada fakta bahwa novel The Buddha in the Attic yang digunakan sebagai objek kajian memuat fenomena migrasi picture brides dan imigran Jepang di Amerika yang senantiasa mengandung wacana sejarah. Dengan demikian, pemaknaan atau interpretasi terhadap wacana yang terkadung dalam The Buddha in the Attic memerlukan pemahaman praktik sosio-kultural yang terkandung dalam teks. Untuk mengumpulkan data, pembacaan novel The Buddha in the Attic melalui metode close reading dilakukan terlebih dahulu. Kemudian data-data yang meliputi kutipankutipan dalam novel yang berkaitan dengan fenomena diaspora para Japanese picture brides dikumpulkan. Setelah data-data mengenai bagaimana fenomena diaspora Japanese picture brides terkumpul, dilakukan pembacaan paralel antara data-data tersebut dengan fakta-fakta sejarah yang terkait, yaitu sejarah mengenai diaspora warga Jepang pada pada rentang waktu 1900-1942 di Amerika untuk mengungkap keterkaitan antara teks dan konteks.

Setelah hasil pembacaan paralel dari The Buddha in the Attic dan sejarah-yang terkait teridentifikasi, dilakukan pengumpulan data yang mencakup bagaimana penggunaan subjek orang ketiga jamak menjadi medium sang pengarang untuk membangun narasi mengenai kehidupan Japanese picture brides dan imigran Jepang secara kolektif di Amerika. Selain pembacaan paralel antara The Buddha in the Attic dan sejarah terkait, dilakukan pula analisis terhadap latar belakang Julie Otsuka sebagai pengarang untuk menunjang rigidnya analisis mengenai narasi mengenai kehidupan Japanese picture brides dan imigran Jepang secara kolektif di Amerika. Hal ini menjadi cukup signifikan karena dalam sebuah penciptaan karya sastra, pengarang sebagai subjek kolektif dipengaruhi dan memengaruhi satu sama lain melalui interaksi yang dilakukan dengan budaya, tradisi, dan komunitasnya. Artinya, dalam proses kreatif, pasti akan ada rekonstruksi dan identifi- 
kasi post-memori yang dilakukan pengarang. Hal ini akan terlihat dari narasi-narasi mengenai picture brides dan imigran Jepang yang diceritakan dalam novel The Buddha in the Attic. Dalam tahapan ini, sumber-sumber seperti biografi pengarang sebagai imigran Jepang generasi ketiga (sansei), artikel surat kabar, video, dan artikel wawancara akan digunakan sebagai alat bantu analisis.

\section{Jejak Diaspora Picture Brides dan Imigran} Jepang Generasi Pertama dan Kedua di Amerika Serikat

Jejak-jejak diaspora warga Jepang di Amerika Serikat merupakan fenomena sejarah yang dieksplorasi dalam plot The Buddha in the Attic karya Julie Otsuka. Melalui pembacaan paralel antara teks (novel) The Buddha in the Attic dan konteks (sejarah migrasi picture brides dan juga warga Jepang di Amerika), studi ini bertujuan untuk mengungkap jejak-jejak diaspora warga Jepang, terutama para picture brides, yang dihadirkan sebagai sebuah bentuk manifestasi dari upaya dokumentasi fenomena sejarah sehingga The Buddha in the Attic tidak hanya sekadar karya sastra, tetapi juga sebagai dokumentasi sejarah migrasi picture brides dan imigran Jepang (Nikkei-jin) yang kelam di Amerika.

Proses migrasi warga Jepang ke Amerika Serikat dimulai dari era Meiji Restoration (1868) yang mengizinkan warga negara Jepang untuk bekerja di Hawai'i. Adalah Immigran Convention (1885) antara pemerintah Jepang dan Hawai'i yang menjadi awal migrasi besar-besaran warga Jepang ke pesisir Amerika Serikat. Sekitar 29.000 warga Jepang, semuanya berjenis kelamin laki-laki, menandatangani kontrak kerja selama tiga tahun untuk bekerja sebagai buruh perkebunan di Hawai'i (Tsutsui, 2007). Para imigran Jepang di Amerika Serikat ini merupakan dekasegi (migrant workers) yang berharap dapat meraih kesuksesan di Amerika Serikat sehingga dapat kembali ke Jepang dengan kekayaan melimpah (Okihiro, 2001: 23).

Selain laki-laki, para perempuan Jepang pun juga melakukan proses migrasi ke Amerika Serikat dengan menjadi picture brides. Picture brides merupakan sebutan kepada para wanita yang melakukan praktik picture marriage atau sanshin kekkon. Beberapa juga menyebut picture brides sebagai mail order brides atau photograph brides. Hal ini karena medium yang digunakan untuk menentukan calon pasangan hidup mereka adalah foto yang dikirim melalui surat. Fenomena serupa juga diceritakan dalam The Buddha in the Attic pada bab pertama yang berjudul "Come Japanese!". Dalam bab ini diceritakan para wanita Jepang yang menjadi picture brides yang datang ke Amerika dengan menggunakan kapal.

SOME OF US on the boat were from Kyoto, and were delicate and fair, and had lived our entire lives in darkened rooms at the back of the house. Some of us were from Nara... Some of us were farmers' daughters from Yamaguchi ... Some of us were from a small mountain hamlet in Yamanashi ... Some of us were from Tokyo ... Many more of us were from Kagoshima and spoke in a thick southern dialect that those of us from Tokyo pretended we could not understand. Some of us were from Hokkaido, where it was snowy and cold, and would dream of that white landscape for years. Some of us were from Hiroshima (Otsuka, 2011: $1-3)$.

Pengenalan latar belakang para picture brides dalam bab ini tidak terlepas dari realitas 
Poetika: Jurnal Ilmu Sastra

Vol. VII No. 2, Desember 2019

picture marriage yang terjadi sekitar tahun 1900-an. Berdasarkan rekam sejarah, picture marriage (shashin kekkon) diawali dengan ditemukannya kamera pada tahun 1885. Para perempuan ini rela menikahi laki-laki yang tidak mereka kenal dengan harapan dapat memperoleh kehidupan yang lebih baik di Amerika karena menurut mereka,

... even the most reluctant of us had to admit that it was better to marry a stranger in America than grow old with a farmer from the village. Because in America the women did not have to work in the fields and there was plenty of rice and firewood for all. And wherever you went the men held open the doors and tipped their hats and called out, "Ladies first" and "After you" (Otsuka, 2011: 15).

Berdasarkan kutipan tersebut, tampak bahwa para picture brides memiliki pandangan ideal mengenai Amerika. Mereka menganggap bahwa Amerika adalah sebuah tempat yang mereka dapat memperbaiki kehidupan mereka, misalnya tinggal di desa dan menikahi seorang petani. Berlandaskan pandangan ideal mengenai Amerika yang "ramah" kepada perempuan, mereka membulatkan tekad untuk tetap bertahan agar dapat mencapai daratan yang menawarkan kebebasan dan kesempatan pada perempuan.

Selain pandangan ideal mengenai Amerika, salah satu alasan yang memotivasi mereka untuk bermigrasi ke Amerika di antaranya:

SEVERAL OF US on the boat had secrets, which we swore we would keep from our husbands for the rest of our lives. Perhaps the real reason we were sailing to America was to track down a long-lost father who had left the family years before. ...Or perhaps we were leaving behind a young daughter who had been born to a man whose face we could now barely recall-a traveling storyteller who had spent a week in the village, or a wandering Buddhist priest who had stopped by the house late one night on his way to Mt. Fuji. ... We still felt guilty for hav-
DOI $10.22146 /$ poetika.49352

ISSN 2338-5383 (print); 2503-4642 (online)

ing chosen our own life over hers, and on the boat we wept for her every night for many nights in a row and then one morning we woke up and dried our eyes and said, "That's enough," and began to think of other things. Which kimono to wear when we landed. How to fix our hair. What to say when we first saw him. Because we were on the boat now, the past was behind us, and there was no going back (Otsuka, 2011: 21).

Berdasarkan alasan-alasan pribadi ini, pandangan ideal mengenai Amerika sebagai sebuah suaka untuk mendapatkan kehidupan baru semakin diperkuat. Alih-alih menyesali keputusan, para perempuan ini justru memilih untuk tetap optimis karena berpandangan bahwa mereka telah meninggalkan masa lalu. Fenomena yang dialami oleh para Japanese picture brides ini juga disebut oleh Younho Oh (2017: 1643) sebagai voluntary exile sebab para picture brides ini meninggalkan negara asalnya atas kemauan (volition) mereka sendiri. Berdasarkan pendapat Oh ini, apabila dicermati dengan saksama, kutipan tersebut memiliki indikasi tersendiri mengenai konsep voluntary exile, yaitu meninggalkan negara asal mereka tanpa paksaan karena keinginan pribadi mereka.

Sayangnya, alih-alih menjadi sukses, para picture brides ini dihadapkan pada kerasnya kehidupan di Amerika Serikat, seperti halnya diceritakan pada bab ketiga The Buddha in The Attic yang berjudul "Whites".

We settled on the edges of their towns, when they would let us. And when they would not-Do not let sundown find you in this county, their signs sometimes said-we traveled on. We wandered from one labor camp to the next in their hot dusty valleys - the Sacramento, the Imperial, the San Joaquin-and side by side with our new husbands, we worked their land. . And when the harvest season was over we tied our blanket rolls onto our backs and, cloth bundles in hand, we waited for the next wagon to come, and we traveled on (Otsuka, 2011: 40). 
Poetika: Jurnal Ilmu Sastra

Vol. VII No. 2, Desember 2019

Kutipan tersebut merupakan cerminan dari kehidupan nyata para picture brides dan suami mereka yang mengalami perlakuan tidak adil dari warga Amerika Serikat. Perbedaan budaya yang kontras antara budaya Jepang dan Amerika akhirnya memaksa mereka untuk meninggalkan nilai-nilai tradisional mereka sebagai perempuan Jepang, dan mengadaptasi kebiasaan baru sebagai perempuan Amerika. Tindakan yang demikian, dikenal dengan konsep melting pot dan acap kali dilakukan oleh para imigran yang menetap di Amerika sebagai sebuah upaya agar mereka dianggap sebagai warga negara Amerika Serikat (Americans).

Proses melting pot ini juga disebut sebagai Americanization yang disinyalir sebagai sebuah upaya untuk menjaga budaya Amerika agar tetap homogen (Gloor, 2006: 29). Senada dengan pendapat ini, Kivisto (2004: 151) mengkritik bahwa melting pot sejatinya merefleksikan budaya dari masyarakat yang dominan, bukan sebagai sebuah bentuk masyarakat yang terintegrasi dari beberapa budaya yang saling membaur. Bentuk asimilasi kebudayaan yang demikian dipandang sebagai jalan satu arah karena bergantung pada kooperativitas para imigran yang diorientasikan untuk menyerupai kultur dominan dari masyarakat British American atau disebut dengan Anglo-conformity.

Sayangnya, adaptasi yang mereka lakukan gagal karena perbedaan ras dianggap sebagai salah satu wujud "alien" yang sungguh berbeda dengan mayoritas warga Amerika. Kondisi yang demikian terlihat ketika para imigran Jepang yang dipekerjakan di perke-
DOI 10.22146/poetika.49352 ISSN 2338-5383 (print); 2503-4642 (online)

bunan harus berpindah lokasi tempat tinggal karena

THEY DID NOT want us as neighbors in their valleys. They did not want us as friends. ... Sometimes they drove by our farm shacks and sprayed our windows with buckshot, or set our chicken coops on fire. Sometimes they dynamited our packing sheds. Sometimes they burned down our fields just as they were beginning to ripen and we lost our entire earnings for that year. ... And after that our husbands were never the same. ... At night we slept with our shoes on, and hatchets beside our beds, while our husbands sat by the windows until dawn. Sometimes we were startled awake by a sound but it was nothing-somewhere in the world, perhaps, a peach had just dropped from a tree-and sometimes we slept straight through the night and in the morning when we woke we found our husbands slumped over and snoring in their chairs and we tried to wake them gently, for their rifles were still resting on their laps. Sometimes our husbands bought themselves guard dogs, which they named Dick or Harry or Spot, and they grew more attached to those dogs than they ever did to us, and we wondered if we had made a mistake, coming to such a violent and unwelcoming land. Is there any tribe more savage than the Americans? (Otsuka, 2011: 60).

Perlakuan tidak menyenangkan yang dialami oleh para picture brides ini memaksa mereka berpindah ke pinggiran kota untuk menjadi pelayan. Di tempat tinggal baru mereka, para perempuan ini belajar menggunakan telepon dan faucet, menyambut tamu dengan berjabat tangan, merokok, dan mengeriting rambut bak Mary Pickford. Semua hal baru ini diajarkan oleh majikan perempuan mereka dan para picture brides ini merasa bersyukur karena memiliki 'teman' baru yang menerima mereka. Akan tetapi, di sisi lain mereka juga merasa iri karena majikan-majikan perempuan mereka ini nampak begitu bebas, santai, dan percaya diri. Para picture brides ini juga mengagumi penampilan majikan mereka yang semampai dan cantik karena warna rambut yang beragam. Sebagian dari picture brides ini juga pindah ke J-Town di mana mereka membuka usaha penatu. 
Poetika: Jurnal Ilmu Sastra

Vol. VII No. 2, Desember 2019

Tidak hanya merasa sebagai "alien", para picture brides dan suami mereka ini juga dianggap sebagai "traitors" oleh warga Amerika Serikat. Mereka dianggap sebagai matamata Jepang yang merupakan "enemy collaborators" dan akhirnya ditangkap satu per satu.

IT WAS ALL, of course, because of the stories in the papers. They said that thousands of our men had sprung into action, with clockwork precision, the moment the attack on the island had begun. They said we had flooded the roads with our run-down trucks and jalopies. They said we had signaled to the enemy planes with flares from our fields. They said that the week before the attack several of our children had bragged to their classmates that "something big" was about to happen. They said that those same children, when questioned further by their teachers, had reported that their parents had celebrated the news of the attack for days. They were shouting banzais. They said that in the event of a second attack here on the mainland anyone whose name appeared on the list would more than likely rise up to assist the enemy. They said that our truck farmers were foot soldiers in a vast underground army. They've got thousands of weapons down below in their vegetable cellars. They said that our houseboys were intelligence agents in disguise. They said that our gardeners were all hiding shortwave radio transmitters in their garden hoses and when the Pacific zero hour struck we'd get busy at once. Burst dams. Burning oil fields. Bombed bridges. Blasted roads. Blocked tunnels. Poisoned reservoirs. And what was to stop one of us from walking into a crowded marketplace with a stick of dynamite tied to our waist? Nothing (Otsuka, 2011: 134-135).

Kejadian ini kemudian berujung pada Japanese Interment (1942) yang mewajibkan mereka untuk tinggal di kamp-kamp pengasingan. Fenomena prejudice terhadap para imigran Jepang ini dikemas pada subbab yang berjudul Last Day

Others of us remained quiet and prepared to leave as best we could. We sent notes to our children's teachers, apologizing to them in our broken English for our children's sudden and unexpected absence from school. . . We packed our bags. We gathered up our children and from every town in every valley
DOI $10.22146 /$ poetika.49352

ISSN 2338-5383 (print); 2503-4642 (online)

and every city up and down the coast, we left. And we knew it would only be a matter of time until all traces of us were gone (Otsuka, 2001: 162).

Kepergian para imigran Jepang ini akhirnya menyisakan "only hearsay, and none of it necessarily true." Mereka pun akhirnya dianggap telah lenyap dan orang-orang "shall probably not meet them again in this world" (Otsuka, 2001: 201).

Identifikasi bahwa imigran Jepang ini dianggap telah lenyap tersebut sejatinya memiliki kaitan dengan peristiwa eksklusi yang dilakukan pemerintah Amerika pada masa Perang Dunia II. Tindakan eksklusi terhadap imigran Jepang di Amerika pada awalnya direkomendasikan kepada sekretaris Henry L. Stimson, oleh Letnan Jenderal John L. Dewitt, Panglima Komando Pertahanan Barat dengan tanggung jawab untuk keamanan di pesisir barat Amerika. Presiden Roosevelt kemudian menyetujui rekomendasi Stimson dan kemudian memerintahkan untuk mengeluarkan The Executive Order 9066. The Executive Order 9066 ini sejatinya bertentangan dengan premis dasar Amerika, yaitu bahwa kesetiaan kepada Amerika Serikat adalah masalah pilihan individu dan tidak ditentukan oleh ikatan dengan negara asal para imigran. Tidak hanya itu, berdasarkan rekomendasi dari Jenderal DeWitt jelas tidak memberikan alasan yang cukup kredibel untuk melakukan tindakan eksklusi terhadap imigran Jepang di Amerika (1983: 293-301).

Oleh karena itu, dampak kebijakan evakuasi dan relokasi yang dilakukan oleh Pemerintah Amerika sungguh berdampak dalam kehidupan para imigran Jepang di Amerika. Meskipun sudah bertahun-tahun semenjak peristiwa kelam 
tersebut, kebanyakan dari para imigran Jepang masih menyimpan rasa ketakutan tersendiri karena cara mereka melihat diri mereka sendiri, bagaimana mereka melihat Amerika, dan bagaimana mereka membesarkan keturunan mereka. Fenomena traumatis ini merupakan refleksi dari apa yang Okihiro sebut dengan "the culmination of nearly a century of anti-Asian agitation and racial discrimination in America" (2001: 171).

\section{Penggunaan Subjek Orang Pertama Jamak dan Narasi tentang Kehidupan Imigran Jepang (Nikkei-jin) di Amerika Serikat}

Sebagai bentuk lebih lanjut dari pembahasaan akan jejak-jejak diaspora picture brides tersebut, studi ini berupaya membuktikan bahwasanya dengan pembacaan paralel antara teks dan konteks, The Buddha in the Attic juga merupakan sebuah bentuk pembangunan narasi akan kehidupan imigran Jepang (Nikkei-jin) di Amerika Serikat yang selama ini kurang diketahui dan diberi perhatian khusus. Pembangunan narasi ini sejatinya diwujudkan dengan penggunaan subjek jamak orang pertama (first person plural) yaitu "we" yang dapat ditemukan pada bab satu hingga bab ketujuh.

Merupakan hal yang menarik ketika novel pada umumnya memiliki karakter protagonis yang biasanya sekaligus berfungsi sebagai narator untuk menceritakan dan menghidupkan plot, The Buddha in the Attic justru tidak memiliki satu pun karakter utama. Subjek "we" dalam The Buddha in the Attic berperan sebagai alat narasi untuk menjalankan plot juga mewakili para perempuan
Japanese picture brides sebagai narator. Tidak adanya tokoh utama dalam novel ini merupakan upaya untuk memberi jarak antara pembaca dan narator dalam novel The Buddha in the Attic, yang berusaha untuk memunculkan narator yang berbeda dengan seorang karakter utama atau protagonis. Maka, gaya narasi dengan menggunakan subjek " $w e$ " ini memiliki tendensi untuk memperjelaskan posisi narator dan pembaca. Fenomena ini, seperti yang diutarakan oleh Fujii (1993) dalam konteks kajian sastra Jepang, selalu berkaitan dengan diskusi mengenai hubungan antara narator, karakter, dan pembaca beserta kaitannya dengan karakteristik bahasa Jepang yang berorientasi kepada pendengar atau audiens.

Melihat secara restropektif, gaya penulisan yang bersifat memberi ruang bagi narator dan pembaca ini memiliki kaitan yang erat dengan fenomena Genbun-itchi yang menandai masuknya era modernisme. Genbun-itchi yang merupakan sebuah upaya untuk menyelaraskan bahasa tertulis (written language) dengan bahasa lisan (spoken language) memiliki ciri khas, yaitu menggunakan pemilihan kata yang bersifat sederhana dan mundane. Genbun-itchi menjadi dasar untuk gaya penulisan yang lebih sederhana (colloquial written style).

Pada era Tokugawa yang erat dengan kebijakannya untuk membagi batasan-batasan untuk masing-masing wilayah, telah mengakibatkan lambatnya perkembangan bahasa. Sebagai imbasnya, terciptalah dialek-dialek yang kompleks. Pada tahun 1871, kebijakan tersebut digantikan oleh kebijakan yang mengatur ulang pembagian batas-batas wilayah. Kebijakan ini 
juga mewajibkan wilayah-wilayah tersebut untuk berada langsung di bawah pengawasan pemerintah yang terpusat di Tokyo. Dengan kebijakan baru pada era Meiji ini, terciptalah kebebasan baru interaksi sosial karena orang -orang dapat melakukan perjalanan ke luar daerah asal mereka.

Pada saat yang bersamaan, batasan antara empat kelas sosial, yaitu kesatria, perajin, petani, dan pedagang secara resmi ditiadakan sehingga siapa pun yang memiliki kemampuan dan talenta dapat mengisi posisi-posisi tersebut. Sebagai lanjutan dari kebijakan ini, muncullah kebutuhan mendesak akan gaya penulisan yang berdasarkan pada bentuk standard speech yang digunakan dalam kegiatan sehari-hari. Seiring dengan pertimbangan praktis untuk mereformasi bahasa tulis, para intelek, dalam hal ini sastrawan, juga memandang bahwa hal ini akan memfasilitasi penyebaran ajaran mereka kepada massa yang lebih luas. Mereka menyadari bahwa dengan mereformasi gaya penulisan yang menekankan pada kesederhanaan dan kejelasan tata bahasa maka hal ini akan dapat dicapai (Twine, 1978: 344).

Dengan mempertimbangkan bahwa gaya narasi dalam The Buddha in the Attic menggunakan diksi dan gramatika yang sederhana, dapat dikatakan bahwa ia berupaya mengikuti cara penarasian novel yang dipengaruhi oleh genbun-itchi. Dengan menggunakan gaya penulisan yang sederhana, narasi para picture brides ini menawarkan "a compelling story and a more intimate sense" (Shirane, Suzuki, \& Lurie, 2016: 589) sehingga audiens merasa seolah-olah mereka sedang melakukan komunikasi langsung dengan para picture brides.

Selain dipengaruhi oleh adanya Genbunitchi, penggunaan subjek "we" juga memiliki kaitan dengan tradisi masyarakat Jepang yang menjunjung konsep komunikasi interpersonal. Komunikasi interpersonal yang dimaksud dalam hal ini adalah kebiasaan untuk merujuk diri sendiri sebagai bagian dari masyarakat atau secara kolektif. Penggunaan subjek bentuk jamak orang pertama ini tidak semata-mata dilakukan Otsuka hanya untuk merepresentasikan kesulitan-kesulitan yang dialami oleh imigran Jepang secara kolektif, tetapi juga untuk merepresentasikan tradisi Jepang yang disebut dengan shūdanshugi yang berarti kelompok. Shüdanshugi sendiri secara harafiah memiliki makna "hidup secara berkelompok". Shūdanshugi kemudian dipahami lebih lanjut sebagai sebuah bentuk kesadaran dalam kehidupan berkelompok yang menciptakan keharmonisan sehingga melahirkan rasa saling memiliki dan rasa kebersatuan seorang individu dengan kelompoknya (Fujiwara, 2018: 318).

Apabila diperhatikan lebih lanjut, latar belakang Julie Otsuka sebagai warga Amerika keturunan Jepang memengaruhi narasi dalam The Buddha in the Attic. Perlu menjadi pertimbangan bahwa The Buddha in the Attic ditulis berdasarkan pengalaman keluarga Otsuka sebagai Nikkei-jin (imigran Jepang) di Amerika pada masa Perang Dunia II. Dalam sebuah interview, Otsuka merasakan "subterranean anger that has been passed down" apabila mengingat perlakuan pemerintah Amerika terhadap imigran Jepang kala itu. 
Poetika: Jurnal Ilmu Sastra

Vol. VII No. 2, Desember 2019
DOI 10.22146/poetika.49352

ISSN 2338-5383 (print); 2503-4642 (online)
It seems clear that what happened to the Japanese here during WWII was wrong, a travesty of justice. Innocent people-over two-thirds of them U.S. citizens-were rounded up and incarcerated without due process for a crime, that of disloyalty, which they did not commit. The government formally apologized in 1988 and reparations have been paid to the surviving internees. Still, it is unacceptable that a government could so easily deprive a people of their civil rights in the name of national security... it was all a big mistake. It happened once but it should not happen again (An Interview with Julie Otsuka, 2011).

Apa yang dialami Otsuka merupakan efek dari post-memory atau rasa trauma personal yang dialami oleh sebuah generasi. Trauma ini tertanam sebagai akibat dari trauma kolektif dan budaya mengenai kelompoknya (Hirsch, 2008). Rasa trauma yang dialami Otsuka sebagai generasi ketiga dari imigran Jepang (sansei) merupakan proyeksi dari memori-memori yang ia dapatkan dari narasi -narasi akan kehidupan issei dan nisei dari kakek-nenek dan kedua orang tuanya.

Diketahui pada pembahasan sebelumnya bahwa pada masa Perang Dunia II, Japanese American dianggap sebagai pembelot oleh mayoritas warga Amerika. Kondisi yang demikian berujung pada Japanese Internment yang mengakibatkan puluhan ribu imigran Jepang ditangkap oleh FBI dan direlokasi ke kamp-kamp pengasingan. Fenomena ini mengakibatkan rasa trauma dan menurut Otsuka sendiri "the war is just an episode they'd rather forget, because of the shame, the stigma they felt at being labeled disloyal." Dari pernyataan Otsuka ini, internalisasi bahwa shuudan shuki para imigran Jepang yang telah menganggap mereka bagian dari warga Amerika, menciptakan rasa luka yang mendalam setelah mereka dibebaskan dari kamp- kamp tersebut. Maka, The Buddha in the Attic merupakan narasi yang mencakup "a very common first-generation story," dan berhasil membuat Otsuka "fascinated by them" (Finding Inspiration in History's Dark Corners, 2011).

Post memory yang Otsuka rasakan ini juga merupakan manifestasi dari shūdanshugi Otsuka sebagai salah satu anggota atau bagian dari kelompoknya, yaitu imigran Jepang di Amerika. Ia merasa bahwa ada banyak cerita menarik yang harus ia ceritakan. Di sisi lain Otsuka juga merasakan bahwa

As a writer and as a Japanese-American, I feel a responsibility, especially now, to remind people of what happened to the Japanese in this country during WWII, because the effects of wartime discrimination can last a lifetime. All these years after the war, my mother still signs off every telephone conversation with, "The FBI will check up on you again soon! (An Interview with Julie Otsuka, 2011).

Adapun terkait dengan penggunaan orang pertama jamak (first person plural), Otsuka berusaha mengakomodasi emosi dari para picture brides dan juga imigran Jepang secara keseluruhan. Penggunaan subjek "we" mengonvensikan budaya kolektif yang selama ini menjadi tradisi atau upbringing masyarakat Jepang.

Using the 'we' voice allowed me to tell a much larger story than I would have been able to tell otherwise. At first I tried telling the story from the point of view of a single picture bride, but this approach felt too narrow and confining... Using the 'we' voice allowed me to weave them all in. It's a very capacious and infinitely expandable voice. Each sentence gives you a brief window into somebody's life - it's like catching a glimpse of someone's house from a train - and then we move on. Also, since Japan is a very group-oriented culture (my father, who immigrated from Japan after World War II, once said to me, 'Japan is the opposite of Ameri$\mathrm{ca}^{\prime}$ - meaning, I think, that here in America, the emphasis is on the individual), it made sense to speak of the picture brides as a collective entity (Julie Otsuka: Interview, 2011). 
Terkait dengan kesadaran Otsuka sebagai salah seorang dari Nikkei-jin, ia berusaha menciptakan narasi bagaimana keharmonisan dapat melahirkan rasa saling memiliki dan rasa kebersatuan seorang individu dengan kelompoknya. Hal ini diwujudkan Otsuka dalam judul novel itu sendiri, The Buddha in the Attic. Dalam ajaran agama Buddha, disebutkan bahwa salah satu kewajiban dari pengikutnya adalah dengan menjaga keharmonisan dan menjadi submissive sekalipun mereka mengalami kesusahan. Hal ini dapat dilihat bahwa warga Amerika keturunan Jepang (Japanese-American) yang mengalami fenomena internment pada saat Perang Dunia II, nyaris tidak pernah membicarakan pengalaman kelam mereka karena,

... they'd rather forget, because of the shame and the stigma they felt at being labeled "disloyal. . . Also, culturally, [they] don't complain, [they] just endure. .. It [also] stigmatized them. It made some of them feel ashamed of being Japanese, ashamed of not being "American" enough. After the war, many Japanese-Americans tried to "blend in" to mainstream (white) America as best they could. They destroyed their Japanese possessions, and they refused to teach their children Japanese, or even talk to them about the war (Julie Otsuka Interview, 2011).

Ajaran Buddha untuk menjadi submissive, atau tunduk, dan menciptakan keharmonisan tersirat secara implisit dalam pernyataan Otsuka mengenai fenomena kelam ini. Dengan berupaya memutuskan relasi mereka dengan hal-hal yang berbau Jepang, para picture brides dan juga para Nikkei-jin secara tidak langsung mencoba untuk tetap menjaga keharmonisan antara diri mereka sebagai kaum minoritas dengan kaum mayoritas dari Amerika. Terlebih, dari upaya inilah muncul sebuah ikatan (bond) khusus yang lahir dari rasa empati akan trauma-trauma yang dialami. Dengan demikian, The Buddha in the Attic merupakan perwujudan nyata bahwa sekalipun ia menceritakan tentang pengalaman kelam picture brides dan Nikkei-jin pada saat Perang Dunia II ia tetap berusaha menjaga keharmonisan dengan menyembunyikan dirinya di loteng (attic) sejarah yang tidak terjamah.

\section{Simpulan}

Dari paparan mengenai jejak-jejak diaspora yang tampak dalam novel The Buddha in the Attic karya Julie Otsuka dan rekam sejarahnya, dapat disimpulkan bahwa terdapat sebuah tendensi untuk menggambarkan liku-liku jejakjejak diaspora para Japanese picture brides yang datang ke daratan Amerika pada tahun 1900 -an. Selain sebagai sebuah fenomena sejarah yang melatarbelakangi plot, jejak diaspora para Japanese picture brides ini juga merupakan sebuah manifestasi dari dokumentasi sejarah para imigran Jepang (Nikkei-jin) di Amerika Serikat yang diciptakan dari post-memory penulisnya, yaitu Julie Otsuka, yang merupakan bagian dari post-generasi dari Japanese Internment pada masa Perang Dunia II.

Lebih lanjut, sebagai hasil dari rekonstruksi sejarah diaspora warga Jepang di Amerika, penggunaan subjek orang pertama jamak ( ${ }^{i}$ irst person plural) mengisyaratkan adanya pembangunan narasi akan kehidupan imigran Jepang (Nikkei-jin), termasuk di dalamnya picture brides, di Amerika. Subjek orang pertama jamak yang digunakan sebagai teknik penceritaan tidak hanya merepresentasikan budaya kolektif yang menjadi tradisi masyarakat Jepang, tetapi juga sebagai usaha Julie Otsuka untuk men- 
Poetika: Jurnal Ilmu Sastra

Vol. VII No. 2, Desember 2019

gonvensikan bagaimana keharmonisan sebagai ciri khas ajaran Buddha yang dianut masyarakat Jepang dapat melahirkan rasa saling memiliki dan rasa kebersatuan seorang individu dengan kelompoknya, sesuai dengan nilai-nilai yang terkandung dalam shūdanshugi.

\section{Daftar Pustaka}

Adams, J. T. 1931. The Epic of America. Boston: Little Brown \& Co.

Amadeo, K. 2019, February 19. What Is the American Dream? The History That Made It Possible. Retrieved April 57, 2019, from The Balance: https:// www.thebalance.com/what-is-theamerican-dream-quotes-and-history3306009

Clark, W. A. 2003. Immigration and the American Dream. In W. A. Clark, Immigrants and the American Dream: Remaking the Middle Class (pp. 5-28). New York: Guilford Publications.

Cullen, J. 2003. THE AMERICAN DREAM: A Short History of an Idea That Shaped a Nation. Oxford: Oxford University Press.

Commission on Wartime Relocation and Internment of Civilians. 1983. Personal Justice Denied. National Park Service.

Damono, S. D. 1978. Sosiologi Sastra: Sebuah Pengantar Ringkas. Jakarta: Departemen Pendidikan dan Kebudayaan.

Fagler, J. 2018. The "Picture Bride Problem": Experiences of and Attitudes Toward Japanese Picture Brides in California 19081920. Dissertation. Georgetown: Georgetown University Press.

Fujii, J. A. 1993. Complicit Fictions: The Subject in the Modern Japanese Prose Narrative. Berkeley: Univ of California Press.

Fujiwara, M. 2018. 日本人と [集団主義]. 317-338.

Gloor, L. B. 2006. From the Melting Pot to the Tossed Salad Metaphor: Why Coercive As-
DOI 10.22146/poetika.49352

ISSN 2338-5383 (print); 2503-4642 (online)

similation Lacks the Flavors Americans Crave. Vol. 60, 29-32. diakses dari https:// hilo.hawaii.edu/campuscenter/hohonu/

volumes/documents/

Vol04x06FromtheMeltingPot.pdf

Hallam, J. 2004. Slavery and The Making of America. Retrieved May 45, 2019, from Thirteen Media with Impact: https:// www.thirteen.org/wnet/slavery/ experience/family/history.html

Hirsch, M. 2012. The Generation of Postmemory: Writing and Visual Culture After the Holocaust. New York: Columbia University Press .

Jefferson, T. 1776, July 04. The Declaration of Independence $4^{\text {th }}$ July 1776. Retrieved May 01, 2019, from National Humanities Center: americainclass.org

Kaplan, L. E. 2009. The Making of the American Dream : An Unconventional History of the United States from 1607 to 1900. New York: Algora Publishing.

Kivisto, P. 2004. What is the Canonical Theory of Assimilation? Journal of the History of the Behavioral Sciences 40.2, 149-163.

Klemm, D. 1983. The hermeneutical theory of Paul Ricoeur. London: Associated University Presses.

Kramer, L., \& Maza, S. 2006. A Companion to Western Historical Thought. Malden: Blackwell Publishing.

Lee, C. 2003. Prostitutes and Picture Brides: Chinese and Japanese Immigration, Settlement, and American NationBuilding, 18701920. Working Paper 70, 5-47.

Oh, Y. 2017. "Korean Picture Brides in Hawaii: Historical and Literary Narratives. Journal of Literature and Art Studies, Vol. 7, No. 12, 1632-1644. doi: 10.17265/21595836/2017.12.016.

Okihiro, G. Y. 2001. The Columbia Guide to Asian American History. New York: Columbia University Press.

Otsuka, J. 2011. An Interview with Julie Otsuka.

Otsuka, J. 2011, August 16. Finding Inspiration in History's Dark Corners. (L. Reynolds, Interviewer) 
Otsuka, J. 2011. Julie Otsuka Interview. (A. Duncan, Interviewer)

Otsuka, J. 2011, October 14. Julie Otsuka: Interview. (P. Ryan, Interviewer)

Otsuka, J. 2011. The Buddha in the Attic. New York: Alfred A. Knopf.

Ratna, N. K. 2010. Sastra dan Cultural Studies: Representasi Fiksi dan Fakta. Yogyakarta: Pustaka Pelajar.

Ratna, N. K. 2015. Teori, Metode dan Teknik Penelitian Sastra. Yogyakarta: Pustaka Pelajar.

Sato, K. 2015. 「写真花嫁」と『写真花嫁』 一佐藤 (trans. 'Picture Bride' and Picture Brides: Between Fact and Fiction). 山形大 学紀要 (人文科学) 第 15 巻第 2 号, 123 136.

Shirane, H., Suzuki, T., \& Lurie, D. 2016. THE CAMBRIDGE HISTORY OF JAPANESE LITERATURE. Cambridge: Cambridge University Press.

Swingewood, A. 1987. Sociological Poetics and Aesthetics Theory. London: Palgrave Macmillan.

Tanaka, K. 2000. Photographs of Japanese Picture Brides: Visualizing Immigrants and Practicing Immigration Policy in Early
Twentieth-Century United States. In U.S Immigration in Global Context (pp. 27-57). New York: Routledge.

Tanaka, K. 2009. Marriage as Citizen's Privilege: Japanese Picture Marriage and American Social Justice. Nanzan Review of American Studies, 575-150.

Taum, Y. Y. 1997. Pengantar Teori Sastra. Flores: Nusa Indah.

Tittenbrun, J. 2015. The Myth of American Dream. World Scientific New, 5-16.

Tiwary, N. 2009. New Historicism and Arundhati Roy's Works. Journal of Literature, Culture and Media Studies, 79-96.

Tsutsui, W. M. 2007. A Companion To Japanese History. Oxford: Blackwell Publishing Ltd.

Twine, N. 1978. The Genbunitchi Movement. Its Origin, Development, and Conclusion. Мonumenta Nipponica, Vol. 33 No. 3, 333-356.

Wiyatmi. 2013. Sosiologi Sastra. Yogyakarta: Kanwa Publisher.

Yanagisawa, I. T. 2010. 「写真花嫁」たちの オーラル・ヒストリー 一カリフォルニア 州立大学サクラメント校一世オーラル・ヒ ストリー・プロジェクトより (trans) Oral Histories of "Picture brides". Issei Oral History Project, Japanese American Archival Collection California State University, 61-74. 